\title{
Life-Threatening Infection in Transplant Recipients
}

Daire T. O'Shea, MB BCh, MSc, MRCPI, Atul Humar, MD, MSc, FRCPC*

\section{KEYWORDS}

- Transplant infection $\bullet$ Critical care $\bullet$ Immunosuppression $\bullet$ Opportunistic infection

- Microbiological diagnosis

\section{KEY POINTS}

- Transplant patients represent a heterogeneous and rapidly growing patient group requiring a high index of suspicion for infection.

- Infection is a major posttransplant cause of morbidity and mortality, and new threats continually emerge.

- Individualized assessments of net state of immunosuppression and infection risk are important.

- Aggressive pursuit of an early microbiological diagnosis is crucial; invasive procedures should be used if necessary.

- In the setting of life-threatening infection, reduction or cessation of immunosuppressive therapy whenever possible is an important adjunct to therapy.

\section{INTRODUCTION}

Transplant recipients constitute an increasingly diverse and complex patient cohort. They comprise a heterogeneous patient group undergoing solid organ transplantation (SOT), hematopoietic stem cell transplantation (HSCT), or pancreatic islet cell transplantation, and now also include the emerging group of individuals undergoing vascularized composite allotransplantation, such as limb transplants. Infection remains a major cause of morbidity and mortality in transplant recipients; for example, approximately $17 \%$ to $20 \%$ of the mortality following allogeneic HSCT can be attributed to infection. ${ }^{1-3}$

In SOT where immunosuppressants are prescribed indefinitely, transplant physicians and their patients perpetually negotiate the delicate balance between the risk of graft rejection and infection. Advances in techniques and in modern immunosuppression have improved graft survival but continually unveil new infection challenges

Disclosures: A. Humar has received grant support from Roche and consulting fees from Astellas. Transplant Infectious Diseases, Alberta Transplant Institute, University of Alberta, 6-030 Katz Center for Health Research, 11361-87 Ave, Edmonton, Alberta T6G 2E1, Canada

* Corresponding author.

E-mail address: ahumar@ualberta.ca 
for the patient. ${ }^{4-6}$ The pharmacology of immunosuppression has evolved dramatically in recent years with a plethora of agents now available for physicians to use (Box 1). ${ }^{7}$ Specific agents vary greatly in their mode, intensity, and duration of immunosuppression, adding yet another layer of complexity to the management and prevention of infectious morbidity and mortality in transplant recipients. ${ }^{8}$

The risk of infection in transplant recipients is a dynamic process and numerous influencing factors must be considered during the evaluation of patients (Box 2). The net state of immunosuppression is a central concept in transplantation medicine and represents a key determinant of infectious risk. ${ }^{1,9}$ The net state is a measure of an individual's unique susceptibility to infection and incorporates assessment of several important contributing factors

- Pretransplant diagnosis or treatment (eg, myeloablative conditioning before HSCT)

- Induction therapy used at time of transplantation

- Nature of organ or stem cell transplant received (eg, lung vs liver organ transplant or umbilical cord blood, T-cell-depleted stem cell transplants)

- Dose, duration, and choice of maintenance immunosuppression

- Comorbidities (eg, viral coinfection [hepatitis C virus (HCV), cytomegalovirus (CMV)], malnutrition, end-organ failure [cirrhosis, chronic kidney disease])

- Breaches of the mucocutaneous barrier: indwelling devices, mucositis

The time after transplant is also of key importance (Fig. 1, Table 1). It directly influences the potential pathogens from which an individual patient is at risk. ${ }^{1}$ Following periods of intensification of immunosuppression (eg, due to graft rejection or flare of Graft-versus-host disease [GVHD]) the patient's infection risk is adjusted to reflect earlier time points again after transplantation. In the absence of chronic GVHD requiring ongoing immunosuppression in HSCT recipients, immune restitution can in general be considered complete at 2 years after stem cell transplant. ${ }^{3}$

The authors' learning objective is to review significant posttransplant infections that can necessitate critical care support. For ease of description this discussion is divided into infections presenting early after transplantation and those occurring later after transplantation. A more detailed discussion of specific pathogens will then follow.

Early infections are classified here as

- SOT: those encountered between the transplant procedure and 4 weeks after transplantation

- HSCT: infection occurring in the preengraftment phase

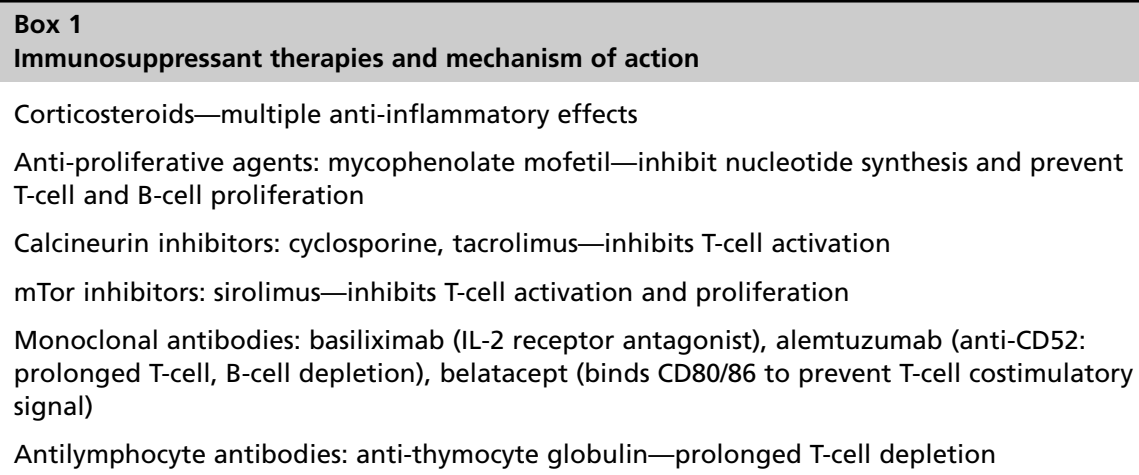

Antilymphocyte antibodies: anti-thymocyte globulin—prolonged T-cell depletion 
Box 2

Infection risk assessment after transplantation

Net state of immunosuppression

Time after transplantation

Type of transplant (highest risk in SOT is lung transplant; in HSCT is T-cell depleted grafts or cord blood stem cell transplants)

HLA mismatch, episodes of graft rejection

Prior antimicrobial exposure: prophylactic/therapeutic

Prior colonization with drug resistant organisms

Prolonged hospitalization

Ongoing neutropenia, lymphopenia, or hypogammaglobulinemia

Infectious entities unique to transplant recipients, and emerging pathogens of importance, are emphasized with the understanding that many more frequently observed infections (dealt with in other articles) are equally applicable to this cohort of patients.

\section{GENERAL PRINCIPLES OF ASSESSMENT}

Transplant recipients are frequent users of critical care services, and the intensivist forms an integral part of posttransplant care pathways. Following SOT, many patients routinely receive their initial period of postoperative care in the critical care setting. In later posttransplant periods these patients can require critical care support for the management of infections manifesting as severe septic shock or in the setting of severe compromise of a vital organ function (eg, pneumonia) or disease affecting the central nervous system (CNS).

Recognition of infection in transplant recipients is notoriously difficult and maintaining a high index of suspicion is of paramount importance. The presentation of infection is frequently altered due to impaired innate and adaptive immune responses. The absence of fever does not preclude the possibility of serious infection and localizing signs may be absent or only identifiable late in the disease process. A multidisciplinary approach is essential to achieve optimal outcomes for patients. This approach involves transplant physicians, transplant surgeons, critical care clinicians, clinical pharmacists, and allied health specialists all working together.

At the core of successful diagnosis and management is a thorough assessment of infectious risk, and a detailed history and physical examination inclusive of cutaneous and ophthalmologic examinations, which can frequently provide subtle but vital diagnostic clues.

Microbiological diagnosis is crucial in this patient group. In the context of extensive differential diagnoses, the value of early and specific diagnostics with the use of invasive procedures if necessary (bronchoscopy, tissue biopsy, or aspiration of collections) to obtain specimens cannot be overemphasized (Box 3). After transplantation, serologic techniques are of limited use because transplant recipients may not mount timely serologic responses. Antigen detection or molecular nucleic acid detection assays are preferred. Adoption of newer microbiological techniques for pathogen identification carries the potential to improve the ability to achieve a definitive diagnosis, greatly enabling the prompt commencement of specific antimicrobials. ${ }^{10,11}$ 


\begin{tabular}{|c|c|c|c|c|}
\hline Time Period & $\begin{array}{c}\text { Pre-engraftment } \\
\text { (day } 0 \text { to day } 10-30^{*} \text { ) }\end{array}$ & $\begin{array}{l}\text { Early post-engraftment } \\
\text { (to day 100) }\end{array}$ & $\begin{array}{l}\text { Mid post-engraftment } \\
\text { (to } 1 \text { year) }\end{array}$ & $\begin{array}{l}\text { Late post-engraftment } \\
\text { (after } 1 \text { year) }\end{array}$ \\
\hline $\begin{array}{l}\text { Infection risk } \\
\text { factors }\end{array}$ & $\begin{array}{c}\text { Neutropenia } \\
\text { Mucositis } \\
\text { Venous catheters }\end{array}$ & $\begin{array}{c}\text { Immunosuppression (aGVHD) } \\
\text { Venous catheters }\end{array}$ & $\begin{array}{l}\text { Immunosuppression } \\
\text { (cGVHD) }\end{array}$ & $\begin{array}{l}\text { Immunosuppression } \\
\text { (cGVHD) }\end{array}$ \\
\hline Type of Infection & $\begin{array}{l}\text { Chemotherapy-associated } \\
\text { and Nosocomial infections }\end{array}$ & Opportunistic infections & $\begin{array}{l}\text { Opportunistic and } \\
\text { Community infections }\end{array}$ & $\begin{array}{l}\text { Community-acquired } \\
\text { infections }\end{array}$ \\
\hline \multirow[t]{4}{*}{ Bacterial } & \multicolumn{2}{|l|}{ Gram positive cocci } & & \\
\hline & \multicolumn{2}{|l|}{ Gram negative rods* } & & \\
\hline & \multicolumn{4}{|c|}{ Encapsulated bacteria } \\
\hline & \multicolumn{4}{|c|}{ Listeria/Salmonella/Nocardia } \\
\hline \multirow[t]{5}{*}{ Viral } & BK virus hemorrhagic cystitis & & \multicolumn{2}{|l|}{$\mathbf{V Z V ^ { \star * }}$} \\
\hline & \multicolumn{2}{|l|}{ HSV } & EBV/PTLD** & \\
\hline & & \multicolumn{2}{|l|}{ CMV $^{*}$} & \\
\hline & & HHV-6/Adenovirus reactivation ${ }^{\star *}$ & & HBV reactivation ** \\
\hline & \multicolumn{3}{|c|}{ Respiratory and enteric viral infections (influenza, RSV, parainfluenza, norovirus) } & \\
\hline \multirow[t]{3}{*}{ Fungal } & Candida* $^{*}$ & & & \\
\hline & Aspergillus & \multicolumn{2}{|c|}{ Aspergillus and other molds (mucorales) $t$} & \\
\hline & & \multicolumn{2}{|l|}{ Pneumocystis jirovecii pneumonia } & \\
\hline \multirow[t]{2}{*}{ Parasitic } & \multicolumn{2}{|c|}{ Strongyloides hyperinfection** } & & \\
\hline & & Toxoplasma reactivation ${ }^{* *}$ & & \\
\hline & & High risk & \begin{tabular}{l|l} 
Low risk & High $r$ \\
\end{tabular} & but prophylaxis typically given \\
\hline
\end{tabular}

Fig. 1. Timeline of infections after hematopoietic stem cell transplant. *Some centers mitigate this risk with prophylaxis. **In previously exposed recipients. ${ }^{\dagger} \mathrm{High}$ risk in those with severe GVHD. ${ }^{\S}$ Timeline described is primarily for those undergoing myeloablative conditioning. (From Marty FM, Baden LR. Infection in the hematopoetic stem cell transplant recipient. In: Soiffer RJ, editor. Hematopoetic stem cell transplantation. Totowa (NJ): Humana Press, 2008. p. 423; with kind permission from Springer Science and Business Media.) 


\begin{tabular}{|c|c|c|c|}
\hline Time Period & 0-1 mo Posttransplant & 1-6 mo Posttransplant & $>6$ mo Posttransplant \\
\hline Type of infection & $\begin{array}{l}\text { Nosocomial infections: pneumonia, } \\
\text { catheter-related, UTI } \\
\text { Postsurgical infections: wound, } \\
\text { anastomotic leaks, abscesses } \\
\text { Donor-derived infection }\end{array}$ & $\begin{array}{l}\text { Opportunistic infection } \\
\text { Reactivation of recipient or donor-latent } \\
\text { infections (prophylaxis may shift further) }\end{array}$ & $\begin{array}{l}\text { Community-acquired infections } \\
\text { In the absence of prophylaxis: reactivation } \\
\text { of latent infections during intense } \\
\text { immunosuppression for acute graft } \\
\text { rejection }\end{array}$ \\
\hline Bacterial & $\begin{array}{l}\text { C difficile colitis } \\
\text { Antimicrobial-resistant bacteria (MRSA, } \\
\text { VRE, ESBL, multi-drug resistant (MDR) } \\
\text { gram-negative rods) } \\
\text { Postsurgical infections (infected biliomas in } \\
\text { liver transplant, pneumonia in lung } \\
\text { transplant, UTI in renal transplant) }\end{array}$ & $\begin{array}{l}\text { Listeria, Nocardia (if no TMP/ } \\
\text { sulfamethoxazole) } \\
\text { M. tuberculosis, Legionella }\end{array}$ & $\begin{array}{l}\text { Ongoing risk for Listeria, Nocardia, } \\
M \text { tuberculosis, Legionella if ongoing } \\
\text { intense immunosuppression } \\
\text { Graft-related infections (cholangitis in liver, } \\
\text { pneumonia in lung, UTI in kidney) } \\
\text { Community-acquired pneumonia } \\
\text { pathogens }\end{array}$ \\
\hline Viral & $\begin{array}{l}\text { In the absence of anti-herpes virus } \\
\text { prophylaxis: HSV } \\
\text { Donor-derived: lymphocytic } \\
\text { choriomeningitis virus, rhabdovirus, } \\
\text { West Nile virus, HIV }\end{array}$ & $\begin{array}{l}\text { BK nephropathy (kidney), HCV reactivation } \\
\text { (liver), adenovirus, respiratory viruses } \\
\text { CMV, EBV, HSV, VZV (after discontinuation } \\
\text { of prophylaxis) }\end{array}$ & $\begin{array}{l}\text { Late-onset CMV (postprophylaxis), EBV- } \\
\text { related PTLD, recurrent HSV, VZV, HCV } \\
\text { progression, JC polyomavirus } \\
\text { Respiratory viruses, enteric viruses, West } \\
\text { Nile virus }\end{array}$ \\
\hline Fungal & $\begin{array}{l}\text { Candida spp } \\
\text { Early Aspergillus only in some settings }\end{array}$ & $\begin{array}{l}\text { Cryptococcus, Aspergillus, atypical molds, } \\
\text { Zygomycetes species } \\
\text { Pneumocystis only if no prophylaxis }\end{array}$ & $\begin{array}{l}\text { During intense immunosuppression in the } \\
\text { absence of antifungal prophylaxis: } \\
\text { Aspergillus, atypical molds, Zygomycetes } \\
\text { species } \\
\text { Geographically restricted endemic fungi }\end{array}$ \\
\hline Parasitic & Uncommon & $\begin{array}{l}\text { Toxoplasma, Strongyloides, Trypanosoma, } \\
\text { Leishmania }\end{array}$ & Ongoing risk if intense immunosuppression \\
\hline
\end{tabular}

From Deepali K, Humar A, editors. The AST handbook of transplant infections. Hoboken (NJ): Wiley Blackwell; p. 3; with permission. 


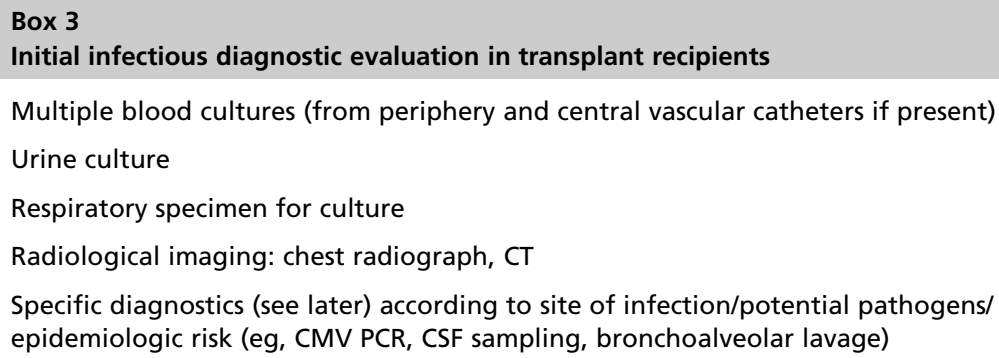

Detailed radiological examinations using computed tomography (CT) scan or magnetic resonance imaging (MRI) allow the early identification of occult sites of infection.

However, in most instances, following the collection of initial specimens for culture, immediate institution of empiric broad antimicrobial coverage targeting the likely pathogens is imperative.

Noninfectious entities can also precipitate illness requiring critical care support in transplant recipients and may mimic infection; these should always be borne in mind. Transplant recipients are susceptible to episodes of graft rejection, GVHD flares, or even recurrence of their primary disease. In addition, adverse effects arising from drug toxicity or drug-drug interactions, which can resemble infectious entities, may be observed (eg, Sirolimus-induced pneumonitis). ${ }^{12,13}$

Effective management of infection after transplantation often necessitates a reduction in immunosuppression if possible. This management alters the net state of immunosuppression in favor of enabling a more robust host immune response. Adjuvant immunotherapy using immunoglobulin is used for certain infections. ${ }^{14}$ Additional therapeutic concerns relate to drug interactions between antimicrobials and immunosuppressant drugs, and appropriate dosing and delivery in the critically ill patient with vital organ dysfunction. ${ }^{13}$ Surgical intervention may be required to aid diagnosis or to effect definitive management.

\section{Early Posttransplantation Period}

In the early period posttransplantation, bacterial infections predominate. Frequent issues arising relate to common nosocomial infectious complications, such as ${ }^{2,15,16}$

- Bloodstream infection (BSI), catheter-associated BSI ${ }^{17}$

- Health care/ventilator-associated pneumonia

- Urinary tract infections (UTI)

- Surgical site infections

- Clostridium difficile-associated diarrhea

The risk of these infections relates to the technical difficulty of the transplant procedure, as well as the pretransplant status of the recipient. The usual nosocomial pathogens prevail, such as Staphylococcus aureus, coagulase-negative staphylococci, enterococci, enterobacteriaceae, and Pseudomonas aeruginosa. As a consequence of significant health care exposure antimicrobial-resistant pathogens (methicillinresistant $S$ aureus [MRSA], vancomycin-resistant Enterococcus [VRE], extended spectrum $\beta$-lactamase [ESBL] -producing gram-negative organisms) are encountered with increased frequency in transplant recipients. ${ }^{18-25}$ In addition, antimicrobial prophylaxis and prior treatment episodes can markedly alter an individual's commensal flora. Thus a heightened awareness of organisms less frequently encountered is 
required and in certain circumstances empiric therapy should take these organisms into consideration (eg. Stenotrophomonas maltophila, Acinetobacter baumannii complex) given the mortality associated with delayed therapy. ${ }^{17,26,27}$

Candida infections and candidemia are frequently encountered in the critical care setting. The prevalence of non-albicans Candida species continues to increase and in transplant recipients this shift can be further promoted by the use of antifungal prophylaxis following HSCT or solid-organ transplantation. ${ }^{28}$

\section{C difficile}

Transplant recipients have an increased incidence of infection because of $C$ difficile and experience more severe disease. The highest incidence is in the first 3 months after transplant. Relapsing disease is common and prolonged courses of therapy are often required. ${ }^{29,30}$

Specific to SOT are the risks of donor-derived infection and infections originating within the operative field.

Donor-derived infection A broad range of potential infecting pathogens can be transmitted by organ transplantation. ${ }^{31}$ These infecting pathogens include the following:

- Known latent infections (eg, CMV, Epstein-Barr virus [EBV])

- Unknown latent infections (eg, tuberculosis, endemic mycoses)

- Infections that are not manifest or detected in the donor at the time of transplantation (eg, bloodstream infections, viral infections such as West Nile virus, ${ }^{32}$ lymphocytic choriomeningitis virus, human immunodeficiency virus [HIV], HCV). ${ }^{33,34}$

Unexplained fever early after transplant with altered mental status or signs of unexplained multiorgan failure despite thorough investigations raises the possibility of donor-derived infection. ${ }^{35}$ Open communication with the relevant organ procurement organizations is vital when such situations arise.

Operative field infections Early posttransplant residual fluid collections or hematomas in conjunction with devitalized tissues or leaking anastomoses can provide the ideal conditions for the establishment of deep-seated infection. Vascular complications such as thrombosis of vessels may also occur, leading to graft ischemia, dysfunction, and necrosis. Early radiological diagnosis and intervention are critical and the approach to diagnosis and management often necessitates surgical intervention for microbiological diagnosis and to perform effective debridement.

\section{ISSUES SPECIFIC TO CERTAIN TRANSPLANT TYPES Cardiothoracic Recipients}

Lung transplant recipients experience the highest frequency of infections among SOT recipients and infection incidence is double that of heart transplant recipients. ${ }^{36,37}$ Contributory factors include

- Donor lung colonization ${ }^{38}$

- Extended periods of intubation

- Disruption of lymphatic drainage

- Reduced cough reflex and ciliary function

- More intensive immunosuppression

Particular attention is paid to the bronchial anastomoses, which can be susceptible to ischemia, breakdown, and infection. Mediastinitis and pleural-based disease are prevalent in cardiothoracic transplant recipients and early imaging with CT is indicated 
when clinical concern exists. ${ }^{39}$ Occasionally culture-negative surgical site infections may be attributable to unusual pathogens such as Mycoplasma hominis. ${ }^{40}$

Cystic fibrosis patients undergoing lung transplantation deserve particular mention. ${ }^{41}$ They often come to transplant colonized with resistant and fastidious organisms; $52 \%$ to $75 \%$ are colonized with multi-drug-resistant Pseudomonas, and $6 \%$ to $9 \%$ are colonized with Burkholderia spp. ${ }^{42-44}$ These patients require individualized antimicrobial prophylactic regimens but breakthrough infection can still occur. This breakthrough infection can manifest as sepsis, empyema, lung abscess, or central venous catheter-associated BSI early or late after transplant. Close surveillance and early aggressive therapy are essential. Antimicrobial therapy should be optimized based on susceptibility testing. Source control, entailing catheter removal or drainage of sites of infection, should be pursued.

\section{Abdominal Organ Transplantation: Liver, Pancreas, Kidney, Intestinal}

In critical care settings, early posttransplantation nosocomial infections again prevail. ${ }^{16}$ Gram-negative bacilli, enterococci, and anaerobic organisms represent the predominant pathogens. Infections related to technical complications are common. These infections may be due to vascular or nonvascular anastomotic problems and a thorough understanding of the transplanted organ anatomy is important. For example, in liver transplant recipients the biliary anastomosis may leak or stricture. Biliary leaks or bilomas represent common sites for the initiation of infection. Thrombosis of the hepatic artery is uncommon but may lead to devastating complications, including hepatic abscesses, necrosis, and sepsis. Early imaging and diagnosis are essential in this setting.

Liver, pancreas, and intestinal recipients are at particular risk for fungal infection most often caused by Candida species. ${ }^{28}$ Close surveillance is required and antifungal prophylaxis is recommended for patients at high risk (intestinal recipient, reoperation, retransplantation, renal failure, massive transfusion, Candida colonization). ${ }^{45,46}$

\section{HSCT Recipients}

During the pre-engraftment phase HSCT recipients most commonly require critical care support due to sepsis or pneumonia. ${ }^{15}$

\section{BSI}

Severe mucositis predisposes to the establishment of BSI by skin, oral, or gastrointestinal (GI) tract flora. Catheter-associated BSI is also common. The spectrum of BSI pathogens has altered over time. Following the introduction of fluroquinolone prophylaxis, the incidence of GNB infection declined but was replaced with increasing incidence of gram-positive organisms. ${ }^{47,48}$ The spectrum reflects the prevailing organisms present within an institution but common to all is a rising incidence of drug-resistant organisms that carry an increased risk of mortality (eg, VRE, ESBLproducing enterobacteriaceae). ${ }^{22}$ Akin to SOT recipients, due consideration should be given to the possibility of unusual bacterial pathogens.

Candida BSI is also increasingly due to non-albicans species reflecting the use of antifungal prophylaxis. Candidemia in transplant recipients should prompt a search for end-organ sites of infection, such as endocarditis, endophthalmitis, renal abscesses, or hepatosplenic candidiasis, depending on the clinical setting. ${ }^{28}$

\section{Pneumonia}

Severe pneumonia occurring pre-engraftment can precipitate the requirement for critical care support. Nosocomial organisms or respiratory viruses cause most pneumonias in this setting; however, these patients are also particularly susceptible to invasive 
fungal infections (IFI). ${ }^{49}$ Prolonged periods of neutropenia pre-HSCT contribute to a substantially increased risk of IFI early post-HSCT. Aspergillus is the most common pathogen encountered with an overall incidence of $5 \%$ to $30 \%$ in allogeneic HSCT recipients. ${ }^{50}$ Other molds, namely Fusarium, Zygomycetes, and Scedosporium spp, are emerging as important causes of IFI in HSCT recipients. ${ }^{28}$ All can manifest with pulmonary and/or disseminated extrapulmonary disease (see more detailed discussion later).

The diverse approaches required to manage pneumonia appropriately due to bacterial, viral, or fungal pathogens in this setting emphasize the importance of early microbiological diagnosis using invasive procedures if necessary.

\section{Typhlitis/neutropenic enterocolitis}

Typhlitis occurs in approximately $5 \%$ of patients with hematologic malignancies. ${ }^{51-53}$ Mucosal injury and profound neutropenia allow secondary bowel wall infection and transmural inflammation. The cecum is most often involved and patients present with right lower quadrant pain or peritoneal signs. Progression to septicemia and/or bowel perforation can occur. Typhlitis is a clinical diagnosis supplemented by CT to confirm and establish the extent of disease or the presence of perforation. Conservative management is the mainstay of therapy with bowel rest, total parenteral nutrition, and broad spectrum antimicrobials to cover gut flora (ie, gram-positive, gram-negative, anaerobic organisms, and fungi while awaiting neutrophil recovery)..$^{53}$ Surgery is recommended only in the case of complications or where conservative management has failed.

\section{LATE INFECTIOUS COMPLICATIONS POSTTRANSPLANTATION}

Late post transplantation, infections which are observed in the early posttransplant period continue to be encountered, but opportunistic pathogens and communityacquired infections tend to dominate. ${ }^{1,9}$ Again, the intensity of ongoing immunosuppression dictates the breadth of pathogens an individual is susceptible to. To maintain relevance to critical care clinicians, common and emerging infection syndromes unique to transplant recipients are discussed and the approach to diagnosis and initial management is reviewed.

Common community infections, which can require critical care support, such as invasive pneumococcal or staphylococcal disease, urosepsis, meningococcal disease, and influenza, have been reviewed elsewhere. Transplant recipients can present at more advanced stages of illness but the management is broadly in keeping with that in immunocompetent individuals. Decisions to adjust immunosuppression or use adjunctive immunoglobulin therapy are based on the patient's individual clinical circumstances.

\section{Pneumonia}

Pulmonary infection is the most common form of documented invasive infection observed in transplant recipients. It will frequently cause sufficient compromise in respiratory function to require critical care support. The differential diagnosis in transplant recipients is very broad (Box 4) and definitive diagnosis is crucial to effective therapy and resolution.

Chest radiograph may often underestimate the true extent of disease and CT thorax can provide further information regarding the extent and pattern of pulmonary involvement, such as the presence of cavitation or nodular infiltrates. Routine diagnostic evaluation with blood cultures remains important but specific tests for opportunistic 


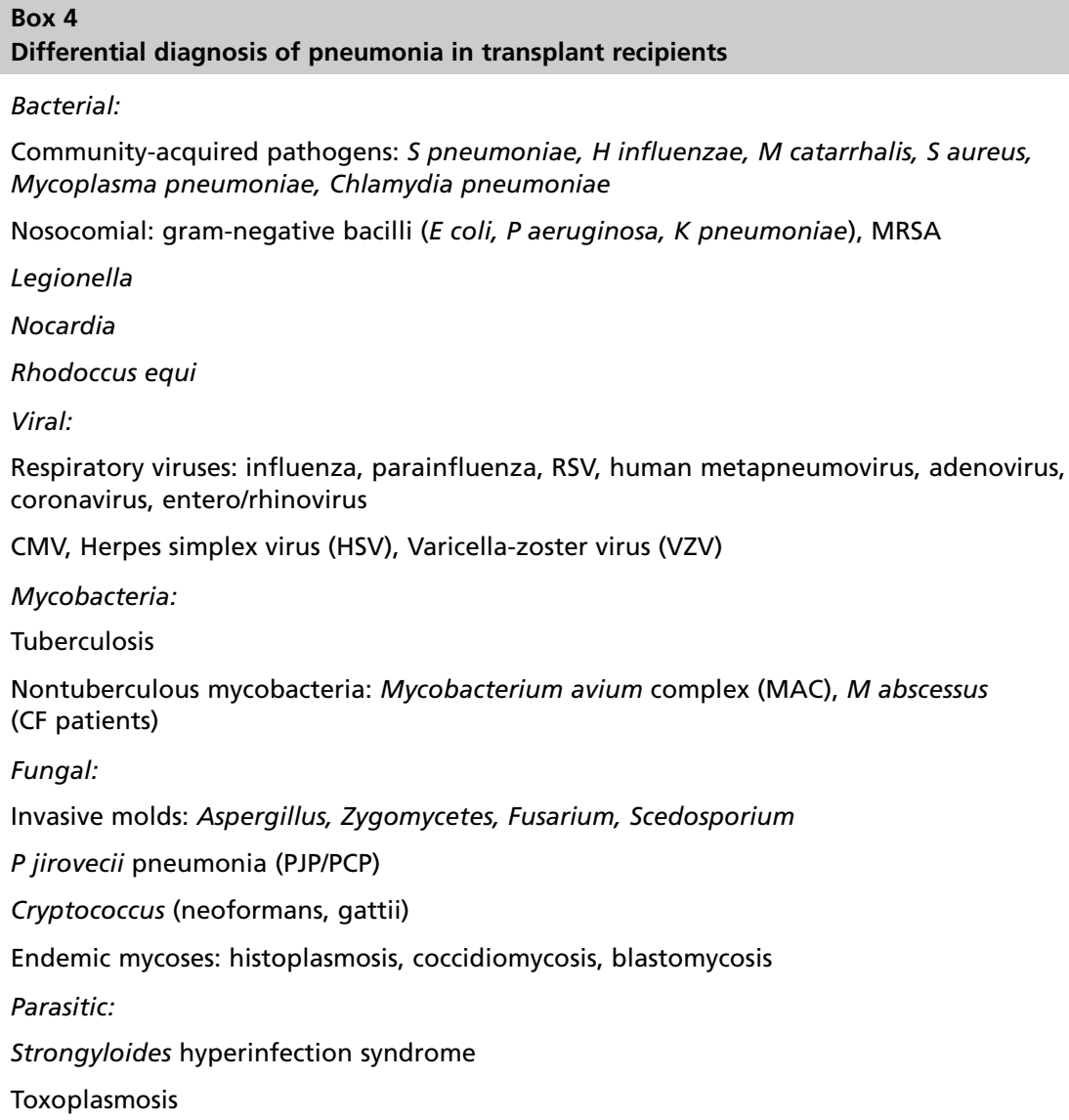

pathogens are equally important (eg, plasma CMV viral load estimation by polymerase chain reaction [PCR], serum galactomannan).

Bronchoalveolar lavage (BAL) yields representative specimens of an adequate quality more reliably than sputum collection. Performing a bronchoscopy and BAL should be considered early with specimens processed for the potential bacterial, mycobacterial, fungal, and viral pathogens (see specific pathogens). Clinicians should also maintain a low threshold for performing a biopsy of involved lung tissue for histology and culture.

\section{Central Nervous System Infection}

Infection of the CNS in transplant recipients can vary from indolent presentations with chronic low-grade headache, to a more fulminant meningoencephalitic presentation requiring admission to critical care. The CNS may be the only site of infection (isolated intracerebral abscess) or it may be involved as part of a disseminated infectious process. In transplant recipients the differential diagnoses for such presentations are diverse and again cover the spectrum from common community acquired to opportunistic pathogens (Box 5). 
Box 5

Differential diagnosis of CNS infection in transplant recipients

Intracerebral abscess/space occupying lesion:

Bacterial: embolic or contiguous disease from local site

Nocardia; Listeria monocytogenes

Fungal: Aspergillus; zygomycetes; Cryptococcus

EBV associated posttransplant lymphoproliferative disorder (PTLD)

Tuberculosis

Toxoplasmosis

Meningoencephalitis:

Bacterial: S pneumoniae; Neisseria meningitides; Listeria

Viral: CMV; EBV; HSV; VZV; HHV6; Enterovirus; JC virus

Fungal: Cryptococcus, Coccidioides, Histoplasma capsulatum

Tuberculosis

Treponema pallidum; Borrelia burgdorferi

$\mathrm{MRI}$ is the neuroimaging modality of choice providing better resolution of the brain parenchyma and improved diagnostic specificity. ${ }^{54}$ Lumbar puncture should be performed if safe, and cerebrospinal fluid (CSF) should be processed for specific pathogen testing (eg, viral PCR, cryptococcal antigen; see specific pathogens).

\section{Enteritis/Colitis}

Occasionally severe enterocolitis may require admission to critical care due to cardiovascular compromise or as a consequence of perforation/bleeding. In transplant recipients the predominant infectious etiologies to consider are

- $C$ difficile

- CMV, EBV (posttransplant lymphoproliferative disorder [PTLD])

- Norovirus, rotavirus: both can cause protracted diarrheal illnesses

- Cryptosporidium, isospora, Giardia lamblia

- Strongyloides stercoralis (hyperinfection syndrome)

Specific diagnostic tests include stool specimens for culture, ova/parasite examination, and $C$ difficile toxin. Enteric virus PCR on stool samples can be performed if available often with improved sensitivity compared with electron microscopy. ${ }^{55}$ Colonoscopy and tissue biopsy may be required to diagnose CMV definitively because in the setting of CMV colitis, CMV may not be detected in plasma by PCR.

\section{SPECIFIC PATHOGENS}

Following is a discussion of selected pathogens that are particularly common causes of life-threatening or severe illness in transplant recipients.

\section{CMV}

$\mathrm{CMV}$ is one of the most prevalent opportunistic pathogens posttransplant. Before the development of sensitive diagnostic tests and the advent of prophylactic/preemptive strategies, CMV reactivation rates of $70 \%$ to $80 \%$ were observed with significant attributable morbidity and mortality. ${ }^{56,57}$ Currently, with the widespread use of 
prophylaxis and preemptive prevention strategies, mortality due to CMV has declined substantially. Despite these advances, CMV remains an important pathogen after transplantation. Seronegative SOT recipients of CMV-seropositive organs are the group at highest risk for severe CMV disease. ${ }^{58}$ In HSCT, seropositive recipients receiving stem cells from a seronegative donor represent the highest risk group. ${ }^{59}$

CMV after transplantation can manifest clinically in several ways

- Fever alone

- CMV syndrome: fever with evidence of myelosuppression, arthralgias, myalgias

- Invasive disease: pneumonitis, enterocolitis, encephalitis, hepatitis (retinitis is rare)

CMV is most frequently detected 1 to 4 months after transplant but late-onset disease is being increasingly reported, the natural history being altered by the use of antiviral prophylaxis. ${ }^{60,61}$

\section{Diagnosis}

CMV DNA in plasma can be rapidly detected by quantitative PCR. Alternatively, an antigen-detection assay (pp65 antigenemia test) is available. Histology remains the gold standard to prove tissue invasive disease but is often only necessary to diagnose colitis when occasionally CMV DNA can be undetectable in the plasma by PCR. ${ }^{58}$ CMV PCR can also be performed on clinical samples from other sites of infection, such as CSF.

\section{Treatment}

Severe disease is best treated initially with intravenous ganciclovir $5 \mathrm{mg} / \mathrm{kg}$ every 12 hours. $^{62,63}$ Initial oral valganciclovir is only an option in patients with mild or no symptoms. ${ }^{64}$ The dose of both agents requires adjustment in the setting of renal impairment. Patients often require a reduction in immunosuppression if possible. CMV immunoglobulin (cytogam) may have additive benefit in severe disease and in particular for CMV pneumonitis. ${ }^{14}$ Recommended dosing is 100 to $150 \mathrm{mg} / \mathrm{kg} 3$ times per week. ${ }^{62}$ Treatment is continued until resolution of viremia.

\section{EBV-associated PTLD}

EBV and associated PTLD cause a wide spectrum of clinical conditions ranging from uncomplicated infectious mononucleosis to true malignant disorders. ${ }^{65}$ The estimated incidence of PTLD is $3 \%$ to $10 \%$ in SOT recipients and up to $18 \%$ in high-risk HSCT recipients (HLA mismatch, GVHD, T-cell-depleted transplants). ${ }^{66-68}$ Attributable mortality approaches $40 \%$ to $60 \%$. This entity most often manifests as a nonspecific febrile illness. Approximately $25 \%$ of patients have involvement of the GI tract. CNS disease can on occasion lead to a fulminant course and dramatic presentations requiring critical care support.

\section{Diagnosis}

Quantitative EBV viral load testing can be performed on whole blood, plasma, and CSF if indicated. ${ }^{69,70}$ Radiological assessment/staging requires positron emission tomography -CT scanning and brain MRI. Adequate tissue sampling and histologic staining for morphology and in situ hybridization studies confirm the diagnosis.

\section{Treatment}

Many different modalities can be used for treatment.

- Reduction of immunosuppression

- Surgical excision of localized lesions (eg, Gl tract masses) 
- Ganciclovir/valganciclovir have variable efficacy

- Adoptive immunotherapy

- Anti-CD20 monoclonal antibody (Rituximab)

- Cytotoxic chemotherapy

\section{Respiratory Viruses}

Respiratory syncytial virus (RSV), parainfluenza, influenza, human metapneumovirus, adenovirus, entervirus, rhinovirus, coronavirus

These common respiratory viruses are frequently encountered in transplant recipients and attack rates follow the usual seasonal pattern. ${ }^{71}$ In immunocompetent individuals most cause only mild symptoms but progression to involvement of the lower respiratory tract and more severe disease occurs with increased frequency in transplant recipients. ${ }^{72,73}$ Pediatric patients are at higher risk for both infection and severe disease. $^{74}$

\section{Diagnosis}

Specific viruses can be detected by direct fluorescence antibody, culture, or multiplex PCR from nasopharyngeal swabs or BAL specimens. ${ }^{71}$

\section{Treatment}

Aside from antiviral therapy for influenza, no consensus exists for the treatment of other respiratory viruses. ${ }^{75}$ Early treatment in certain patients (lung transplant recipients, HSCT patients preengraftment) can be used to reduce the risk of lower tract disease and limit severity. ${ }^{76,77}$ Treatments reported to demonstrate efficacy are detailed below.

- RSV: aerosolized Ribavirin \pm intravenous immunoglobulin (IVIg). ${ }^{77}$ Palivizumab (anti-RSV monoclonal antibody) has also provided additive benefit to Ribavirin ${ }^{78}$

- Parainfluenza: aerosolized Ribavirin $\pm \mathrm{IVIg}^{79}$

- Human metapneumovirus: an emerging respiratory pathogen that has been associated with severe, often fatal disease in HSCT recipients. ${ }^{80}$ Aerosolized Ribavirin and IVIg have also been used with some success in case reports ${ }^{81,82}$

- Adenoviridae can cause a wide range of clinical syndromes; self-limited fever, pneumonitis, hepatitis, hemorrhagic colitis. ${ }^{83,84}$ Rarely, adenovirus can cause a severe disseminated disease with multi-organ failure. This manifestation occurs more frequently in pediatric recipients and carries a high mortality. ${ }^{85}$ Treatment options include cidofovir and ribavirin or the experimental drug CMX001. ${ }^{86,87}$

\section{Aspergillus spp}

Aspergillus is the most common cause of IFI in allogeneic HSCT recipients with an incidence of $5 \%$ to $30 \% .{ }^{49,50,88}$ In SOT recipients the incidence is considerably lower, $1 \%$ to $15 \% .^{89,90}$ Mortality attributable to invasive aspergillosis (IA) has varied from $65 \%$ to $92 \%$ in transplant recipients, although it may be lower in the current era. ${ }^{90}$ Risk factors for IA include prolonged neutropenia, lung transplantation, CMV infection, Aspergillus colonization, graft rejection/failure, GVHD, and iron overload.

The lungs and sinuses are the most common sites of disease involvement. Patients can present with fever, chest pain, hemoptysis, or dyspnea. Pulmonary disease can involve lung parenchyma only or present as a more diffuse tracheobronchitis. Sinus disease can cause facial pain and seizures, or focal neurologic signs with extensive disease.

Pulmonary radiologic appearances are best appreciated using CT and include nodules with or without cavitation, or patchy segmental areas of consolidation or ground 
glass change. Disease outside of the respiratory tract can occur with cutaneous involvement or solitary intracerebral abscesses.

\section{Diagnosis}

Sputum culture lacks sensitivity and the isolation of Aspergillus alone does not reflect disease. The gold standard for diagnosis is the demonstration of the organism and angio-invasive disease in tissue biopsies (lung or sinus tissue). ${ }^{90}$ Fungal stain and culture of such specimens to confirm genus and species remain very important in diagnosis particularly now in the era of prophylaxis using second-generation triazoles (voriconazole, posaconazole), which have altered the spectrum of species encountered. ${ }^{91,92}$

Galactomannan is a constituent of the Aspergillus cell wall and is released during hyphal growth. Estimation of galactomannan in serum is widely used but lacks sensitivity. This test appears to perform better in hematological patients than SOT recipients. ${ }^{93}$ Estimating galactomannan in BAL demonstrates superior sensitivity, ${ }^{94}$ and it can also be performed on CSF specimens but has not been widely standardized. The evolution of molecular assays using PCR should add to the ability to achieve a definitive diagnosis. ${ }^{95}$

\section{Treatment}

Voriconazole is now the accepted treatment of choice. ${ }^{96}$ A loading dose of $6 \mathrm{mg} / \mathrm{kg}$ every 12 hours is administered on day 1 followed by maintenance of $4 \mathrm{mg} / \mathrm{kg} 12$ hourly thereafter. The measurement of trough levels is advised after approximately 1 week of therapy (target range, $1-5.5 \mu \mathrm{g} / \mathrm{mL}$ ). ${ }^{97}$ Voriconazole interacts significantly with calcineurin inhibitors and thus levels of these agents must also be closely monitored. A minimum of 12 weeks of therapy is advised and duration can be guided by clinico-radiologic resolution and surveillance galactomannan assays.

Again species confirmation is vital to guide therapy because the susceptibility of different species (Aspergillus terreus, Aspergillus calidoustus) can vary considerably, and novel antifungal combinations may be required. ${ }^{98}$ Surgical intervention is indicated in the context of significant hemoptysis or extensive sinonasal disease.

\section{Other Molds Causing IFI}

These pathogens cause disease that mimics IA and represent a considerable emerging threat in the era of posaconazole/voriconazole prophylaxis. ${ }^{5,28,99}$ Pathogens of note include zygomycetes, fusarium, and scedosporium. ${ }^{100-103}$

\section{Pneumocystis Jirovecci Pneumonia/PCP}

Effective prophylaxis has dramatically reduced the incidence of Pneumocystis jirovecci pneumonia (PJP) in transplant recipients. ${ }^{104}$ However, it remains a pathogen of note and is an important diagnostic consideration in a transplant patient presenting acutely with respiratory failure. ${ }^{105}$ Classically patients present with subacute fever, cough, and dyspnea. The hallmark of PJP remains profound hypoxia with a relative paucity of clinical findings. Chest radiographs may reveal bihilar infiltrates or pneumothoraces but are often quite unremarkable, and CT thorax is more sensitive for diagnosis.

\section{Diagnosis}

Diagnosis is best achieved via the demonstration of the organism in BAL or lung biopsy specimens. ${ }^{106}$ Several specific staining methods can be used including monofluorescent antibody stains, gomori-methanamine silver stain, or Giemsa and Wright 
stains. The infectious burden is generally less in SOT recipients; thus, the diagnostic sensitivity is lower than the $98 \%$ reported in patients with HIV. ${ }^{106}$

\section{Treatment}

Trimethoprim (TMP)/sulfamethoxazole remains the treatment of choice. Recommended dosing is 15 to $20 \mathrm{mg} / \mathrm{kg} / \mathrm{d}$ of the TMP component in 3 to 4 divided doses. ${ }^{105}$ Adverse effects are frequent (rash, nausea, renal impairment) and alternatives include clindamycin (600-900 mg 6-8 hourly) and primaquine (15-30 mg daily); or dapsone (100 mg daily) and TMP (15 mg/kg/d in 3 divided doses). As in HIV, adjunctive corticosteroids are an important consideration and are generally recommended in cases with severe hypoxemia $\left(\mathrm{PaO}_{2}<70 \mathrm{~mm} \mathrm{Hg}\right){ }^{107}$ Doses in the region of 40 to $60 \mathrm{mg}$ twice daily for 1 week followed by a taper over 2 weeks are used.

\section{Strongyloides Hyperinfection Syndrome}

Strongyloides hyperinfection syndrome is a rare but particularly severe manifestation of latent Strongyloides infection primarily reported in SOT recipients. ${ }^{108-110}$ Massive dissemination of filariform larvae to the lungs, liver, heart, and CNS occurs. Concomitant gram-negative BSI or bacterial meningitis is recognized. Patients present with a severe systemic illness and mortality is high. Diagnosis is achieved via detection of the larvae in stool, respiratory secretions, or CSF. Treatment is with ivermectin $200 \mu \mathrm{g} / \mathrm{kg} / \mathrm{d}$ or albendazole $400 \mathrm{mg}$ twice daily. Extended courses are advised in the setting of hyperinfection in transplant recipients.

\section{SUMMARY}

Transplant recipients represent a complex, heterogenous patient population who often require periods of critical care support. Infectious complications precipitate the majority of admissions to critical care post-transplantation, and patients are susceptible to an increasingly diverse array of common and opportunistic infecting pathogens. Clinicians must maintain a high index of suspicion for infection, and conduct early, thorough diagnostic work-up coupled with prompt institution of antimicrobial therapy. Detailed individualized infection risk assessments are central to guiding therapeutic care pathways and optimizing clinical outcomes.

\section{REFERENCES}

1. Fishman JA. Infection in solid-organ transplant recipients. N Engl J Med 2007; 357(25):2601-14.

2. Patel R, Paya CV. Infections in solid-organ transplant recipients. Clin Microbiol Rev 1997;10(1):86-124.

3. Tomblyn M, Chiller T, Einsele $H$, et al. Guidelines for preventing infectious complications among hematopoietic cell transplantation recipients: a global perspective. Bone Marrow Transplant 2009;15(10):1143-238.

4. Vincenti F, Charpentier B, Vanrenterghem $Y$, et al. A phase III study of belatacept-based immunosuppression regimens versus cyclosporine in renal transplant recipients (BENEFIT study). Am J Transplant 2010;10(3):535-46.

5. Nishi SP, Valentine VG, Duncan S. Emerging bacterial, fungal, and viral respiratory infections in transplantation. Infect Dis Clin North Am 2010;24(3):541-55.

6. Peleg AY, Husain S, Kwak EJ, et al. Opportunistic infections in 547 organ transplant recipients receiving alemtuzumab, a humanized monoclonal CD-52 antibody. Clin Infect Dis 2007;44(2):204-12. 
7. Halloran PF. Immunosuppressive drugs for kidney transplantation. N Engl J Med 2004;351(26):2715-29.

8. Issa NC, Fishman JA. Infectious complications of antilymphocyte therapies in solid organ transplantation. Clin Infect Dis 2009;48(6):772-86.

9. Fishman JA. Introduction: infection in solid organ transplant recipients. Am J Transplant 2009;9(Suppl 4):S3-6.

10. Mitsuma SF, Mansour MK, Dekker JP, et al. Promising new assays and technologies for the diagnosis and management of infectious diseases. Clin Infect Dis 2013;56:996-1002.

11. Clerc O, Prod'hom G, Vogne C, et al. Impact of Matrix-Assisted Laser Desorption Ionization Time-Of-Flight Mass Spectrometry (MALDI-TOF) on the clinical management of patients with Gram-negative bacteremia: a prospective observational study. Clin Infect Dis 2012;56:1101-7.

12. Champion L, Stern M, Israel-Biet D, et al. Brief communication: sirolimusassociated pneumonitis: 24 cases in renal transplant recipients. Ann Intern Med 2006;144(7):505-9.

13. Thomas LD, Miller GG. Interactions between antiinfective agents and immunosuppressants. Am J Transplant 2009;9(Suppl 4):S263-6.

14. Reed EC, Bowden RA, Dandliker PS, et al. Treatment of cytomegalovirus pneumonia with ganciclovir and intravenous cytomegalovirus immunoglobulin in patients with bone marrow transplants. Ann Intern Med 1988;109(10): 783-8.

15. Dettenkofer M, Wenzler-Rottele S, Babikir R, et al. Surveillance of nosocomial sepsis and pneumonia in patients with a bone marrow or peripheral blood stem cell transplant: a multicenter project. Clin Infect Dis 2005; 40(7):926-31.

16. Razonable RR, Findlay JY, O'Riordan A, et al. Critical care issues in patients after liver transplantation. Liver Transpl 2011;17(5):511-27.

17. Moreno A, Cervera C, Gavalda J, et al. Bloodstream infections among transplant recipients: results of a nationwide surveillance in Spain. Am J Transplant 2007; 7(11):2579-86.

18. Fishman JA. Vancomycin-resistant Enterococcus in liver transplantation: what have we left behind? Transpl Infect Dis 2003;5(3):109-11.

19. Linares L, Cervera C, Cofan F, et al. Risk factors for infection with extendedspectrum and AmpC beta-lactamase-producing gram-negative rods in renal transplantation. Am J Transplant 2008;8(5):1000-5.

20. Russell DL, Flood A, Zaroda TE, et al. Outcomes of colonization with MRSA and VRE among liver transplant candidates and recipients. Am J Transplant 2008; 8(8):1737-43.

21. Patel R, Allen SL, Manahan JM, et al. Natural history of vancomycin-resistant enterococcal colonization in liver and kidney transplant recipients. Liver Transpl 2001;7(1):27-31.

22. Weinstock DM, Conlon M, lovino C, et al. Colonization, bloodstream infection, and mortality caused by vancomycin-resistant enterococcus early after allogeneic hematopoietic stem cell transplant. Biol Blood Marrow Transplant 2007; 13(5):615-21.

23. van Delden C, Blumberg EA. Multidrug resistant gram-negative bacteria in solid organ transplant recipients. Am J Transplant 2009;9(Suppl 4):S27-34.

24. Munoz P. Multiply resistant gram-positive bacteria: vancomycin-resistant enterococcus in solid organ transplant recipients. Am J Transplant 2009;9(Suppl 4): S50-6. 
25. Garzoni C. Multiply resistant gram-positive bacteria methicillin-resistant, vancomycin-intermediate and vancomycin-resistant Staphylococcus aureus (MRSA, VISA, VRSA) in solid organ transplant recipients. Am J Transplant 2009; 9(Suppl 4):S41-9.

26. Sopirala MM, Pope-Harman A, Nunley DR, et al. Multidrug-resistant Acinetobacter baumannii pneumonia in lung transplant recipients. J Heart Lung Transplant 2008;27(7):804-7.

27. Playford EG, Craig JC, Iredell JR. Carbapenem-resistant acinetobacter baumannii in intensive care unit patients: risk factors for acquisition, infection and their consequences. J Hosp Infect 2007;65(3):204-11.

28. Person AK, Kontoyiannis DP, Alexander BD. Fungal infections in transplant and oncology patients. Infect Dis Clin North Am 2010;24(2):439-59.

29. Riddle DJ, Dubberke ER. Clostridium difficile infection in solid organ transplant recipients. Curr Opin Organ Transplant 2008;13(6):592-600.

30. Albright JB, Bonatti $\mathrm{H}$, Mendez J, et al. Early and late onset Clostridium difficileassociated colitis following liver transplantation. Transpl Int 2007;20(10):856-66.

31. Grossi PA, Fishman JA. Donor-derived infections in solid organ transplant recipients. Am J Transplant 2009;9(Suppl 4):S19-26.

32. Iwamoto M, Jernigan DB, Guasch A, et al. Transmission of West Nile virus from an organ donor to four transplant recipients. N Engl J Med 2003;348(22): 2196-203.

33. Fischer SA, Graham MB, Kuehnert MJ, et al. Transmission of lymphocytic choriomeningitis virus by organ transplantation. N Engl J Med 2006;354(21): 2235-49.

34. Humar A, Fishman JA. Donor-derived infection: old problem, new solutions? Am J Transplant 2008;8(6):1087-8.

35. Morris MI, Fischer SA, Ison MG. Infections transmitted by transplantation. Infect Dis Clin North Am 2010;24(2):497-514.

36. Speich R, van der Bij W. Epidemiology and management of infections after lung transplantation. Clin Infect Dis 2001;33(Suppl 1):S58-65.

37. Mattner F, Fischer $\mathrm{S}$, Weissbrodt $\mathrm{H}$, et al. Post-operative nosocomial infections after lung and heart transplantation. J Heart Lung Transplant 2007;26(3):241-9.

38. Avlonitis VS, Krause A, Luzzi L, et al. Bacterial colonization of the donor lower airways is a predictor of poor outcome in lung transplantation. Eur $\mathrm{J}$ Cardiothorac Surg 2003;24(4):601-7.

39. Abid Q, Nkere UU, Hasan A, et al. Mediastinitis in heart and lung transplantation: 15 years experience. Ann Thorac Surg 2003;75(5):1565-71.

40. Hopkins PM, Winlaw DS, Chhajed PN, et al. Mycoplasma hominis infection in heart and lung transplantation. J Heart Lung Transplant 2002;21(11):1225-9.

41. Flume PA, Egan TM, Paradowski LJ, et al. Infectious complications of lung transplantation. Impact of cystic fibrosis. Am J Respir Crit Care Med 1994;149(6): 1601-7.

42. Dobbin C, Maley M, Harkness J, et al. The impact of pan-resistant bacterial pathogens on survival after lung transplantation in cystic fibrosis: results from a single large referral centre. J Hosp Infect 2004;56(4):277-82.

43. Boussaud V, Guillemain R, Grenet D, et al. Clinical outcome following lung transplantation in patients with cystic fibrosis colonised with Burkholderia cepacia complex: results from two French centres. Thorax 2008;63(8):732-7.

44. Zaidi S, Elidemir O, Heinle JS, et al. Mycobacterium abscessus in cystic fibrosis lung transplant recipients: report of 2 cases and risk for recurrence. Transpl Infect Dis 2009;11(3):243-8. 
45. Cruciani M, Mengoli C, Malena M, et al. Antifungal prophylaxis in liver transplant patients: a systematic review and meta-analysis. Liver Transpl 2006;12(5): 850-8.

46. Eschenauer GA, Lam SW, Carver PL. Antifungal prophylaxis in liver transplant recipients. Liver Transpl 2009;15(8):842-58.

47. Cullen M, Steven N, Billingham L, et al. Antibacterial prophylaxis after chemotherapy for solid tumors and lymphomas. N Engl J Med 2005;353(10):988-98.

48. Bucaneve G, Micozzi A, Menichetti $F$, et al. Levofloxacin to prevent bacterial infection in patients with cancer and neutropenia. N Engl J Med 2005;353(10): 977-87.

49. Neofytos D, Horn D, Anaissie E, et al. Epidemiology and outcome of invasive fungal infection in adult hematopoietic stem cell transplant recipients: analysis of Multicenter Prospective Antifungal Therapy (PATH) Alliance registry. Clin Infect Dis 2009;48(3):265-73.

50. Wald A, Leisenring W, van Burik JA, et al. Epidemiology of aspergillus infections in a large cohort of patients undergoing bone marrow transplantation. J Infect Dis 1997;175(6):1459-66.

51. Morgan C, Tillett T, Braybrooke J, et al. Management of uncommon chemotherapy-induced emergencies. Theoria 2011;12(8):806-14.

52. Davila ML. Neutropenic enterocolitis. Curr Treat Options Gastroenterol 2006; 22(1):44-7.

53. Nesher L, Rolston KV. Neutropenic enterocolitis, a growing concern in the era of widespread use of aggressive chemotherapy. Clin Infect Dis 2012;56: 711-7.

54. Erdogan C, Hakyemez B, Yildirim N, et al. Brain abscess and cystic brain tumor: discrimination with dynamic susceptibility contrast perfusion-weighted MRI. J Comput Assist Tomogr 2005;29(5):663-7.

55. Pang XL, Preiksaitis JK, Lee B. Multiplex real time RT-PCR for the detection and quantitation of norovirus genogroups I and II in patients with acute gastroenteritis. J Clin Virol 2005;33(2):168-71.

56. Hodson EM, Craig JC, Strippoli GF, et al. Antiviral medications for preventing cytomegalovirus disease in solid organ transplant recipients. Cochrane Database Syst Rev 2008;(2):CD003774.

57. Gluckman E, Traineau R, Devergie A, et al. Prevention and treatment of CMV infection after allogeneic bone marrow transplant. Ann Hematol 1992; 64(Suppl):A158-61.

58. Humar A, Snydman D. Cytomegalovirus in solid organ transplant recipients. Am J Transplant 2009;9(Suppl 4):S78-86.

59. George B, Pati N, Gilroy N, et al. Pre-transplant cytomegalovirus (CMV) serostatus remains the most important determinant of CMV reactivation after allogeneic hematopoietic stem cell transplantation in the era of surveillance and preemptive therapy. Transpl Infect Dis 2010;12(4):322-9.

60. Limaye AP, Bakthavatsalam R, Kim HW, et al. Late-onset cytomegalovirus disease in liver transplant recipients despite antiviral prophylaxis. Transplantation 2004;78(9):1390-6.

61. Boeckh M, Leisenring W, Riddell SR, et al. Late cytomegalovirus disease and mortality in recipients of allogeneic hematopoietic stem cell transplants: importance of viral load and T-cell immunity. Blood 2003;101(2):407-14.

62. Kotton CN, Kumar D, Caliendo AM, et al. International consensus guidelines on the management of cytomegalovirus in solid organ transplantation. Transplantation 2010;89(7):779-95. 
63. Asberg A, Humar A, Rollag $\mathrm{H}$, et al. Oral valganciclovir is noninferior to intravenous ganciclovir for the treatment of cytomegalovirus disease in solid organ transplant recipients. Am J Transplant 2007;7(9):2106-13.

64. Humar A, Siegal D, Moussa G, et al. A prospective assessment of valganciclovir for the treatment of cytomegalovirus infection and disease in transplant recipients. J Infect Dis 2005;192(7):1154-7.

65. Green M, Webber S. Posttransplantation lymphoproliferative disorders. Pediatr Clin North Am 2003;50(6):1471-91.

66. Preiksaitis JK. New developments in the diagnosis and management of posttransplantation lymphoproliferative disorders in solid organ transplant recipients. Clin Infect Dis 2004;39(7):1016-23.

67. Allen U, Preiksaitis J. Epstein-Barr virus and posttransplant lymphoproliferative disorder in solid organ transplant recipients. Am J Transplant 2009;9(Suppl 4): S87-96.

68. Gerritsen EJ, Stam ED, Hermans J, et al. Risk factors for developing EBV-related B cell lymphoproliferative disorders (BLPD) after non-HLA-identical BMT in children. Bone 1996;18(2):377-82.

69. Tsai DE, Nearey M, Hardy CL, et al. Use of EBV PCR for the diagnosis and monitoring of post-transplant lymphoproliferative disorder in adult solid organ transplant patients. Am J Transplant 2002;2(10):946-54.

70. Green M, Webber SA. EBV viral load monitoring: unanswered questions. Am J Transplant 2002;2(10):894-5.

71. Ison MG, Michaels MG. RNA respiratory viral infections in solid organ transplant recipients. Am J Transplant 2009;9(Suppl 4):S166-72.

72. Machado CM, Boas LS, Mendes AV, et al. Low mortality rates related to respiratory virus infections after bone marrow transplantation. Bone 2003;31(8): 695-700.

73. Palmer SM Jr, Henshaw NG, Howell DN, et al. Community respiratory viral infection in adult lung transplant recipients. Chest 1998;113(4):944-50.

74. Lee $\mathrm{JH}$, Jang $\mathrm{JH}$, Lee $\mathrm{SH}$, et al. Respiratory viral infections during the first 28 days after transplantation in pediatric hematopoietic stem cell transplant recipients. Clinic 2012;26(5):736-40.

75. Kumar D, Michaels MG, Morris MI, et al. Outcomes from pandemic influenza A $\mathrm{H} 1 \mathrm{~N} 1$ infection in recipients of solid-organ transplants: a multicentre cohort study. Lancet Infect Dis 2010;10(8):521-6.

76. Sparrelid E, Ljungman P, Ekelof-Andstrom E, et al. Ribavirin therapy in bone marrow transplant recipients with viral respiratory tract infections. Bone 1997; 19(9):905-8.

77. Li L, Avery R, Budev M, et al. Oral versus inhaled ribavirin therapy for respiratory syncytial virus infection after lung transplantation. J Heart Lung Transplant 2012; 31(8):839-44.

78. Shah JN, Chemaly RF. Management of RSV infections in adult recipients of hematopoietic stem cell transplantation. Blood 2011;117(10):2755-63.

79. Wendt CH, Weisdorf DJ, Jordan MC, et al. Parainfluenza virus respiratory infection after bone marrow transplantation. N Engl J Med 1992;326(14):921-6.

80. Egli A, Bucher C, Dumoulin A, et al. Human metapneumovirus infection after allogeneic hematopoietic stem cell transplantation. Infection 2012;40(6): 677-84.

81. Bonney D, Razali H, Turner A, et al. Successful treatment of human metapneumovirus pneumonia using combination therapy with intravenous ribavirin and immune globulin. Br J Haematol 2009;145(5):667-9. 
82. Oliveira R, Machado A, Tateno A, et al. Frequency of human metapneumovirus infection in hematopoietic SCT recipients during 3 consecutive years. Bone 2008;42(4):265-9.

83. Ison MG, Green M. Adenovirus in solid organ transplant recipients. Am J Transplant 2009;9(Suppl 4):S161-5.

84. Chakrabarti S. Adenovirus infections after hematopoietic stem cell transplantation: still unravelling the story. Clin Infect Dis 2007;45(8):966-8.

85. Hoffman JA. Adenoviral disease in pediatric solid organ transplant recipients. Pediatrician 2006;10(1):17-25.

86. Howard DS, Phillips IG, Reece DE, et al. Adenovirus infections in hematopoietic stem cell transplant recipients. Clin Infect Dis 1999;29(6):1494-501.

87. La Rosa AM, Champlin RE, Mirza N, et al. Adenovirus infections in adult recipients of blood and marrow transplants. Clin Infect Dis 2001;32(6):871-6.

88. Marr KA, Carter RA, Crippa F, et al. Epidemiology and outcome of mould infections in hematopoietic stem cell transplant recipients. Clin Infect Dis 2002;34(7): 909-17.

89. Cahill BC, Hibbs JR, Savik K, et al. Aspergillus airway colonization and invasive disease after lung transplantation. Chest 1997;112(5):1160-4.

90. Singh N, Husain S. Invasive aspergillosis in solid organ transplant recipients. Am J Transplant 2009;9(Suppl 4):S180-91.

91. Cornely OA, Maertens J, Winston DJ, et al. Posaconazole vs. fluconazole or itraconazole prophylaxis in patients with neutropenia. N Engl J Med 2007;356(4): 348-59.

92. Ullmann AJ, Lipton $\mathrm{JH}$, Vesole $\mathrm{DH}$, et al. Posaconazole or fluconazole for prophylaxis in severe graft-versus-host disease. N Engl J Med 2007;356(4): 335-47.

93. Pfeiffer CD, Fine JP, Safdar N. Diagnosis of invasive aspergillosis using a galactomannan assay: a meta-analysis. Clin Infect Dis 2006;42(10):1417-27.

94. Maertens J, Maertens V, Theunissen K, et al. Bronchoalveolar lavage fluid galactomannan for the diagnosis of invasive pulmonary aspergillosis in patients with hematologic diseases. Clin Infect Dis 2009;49(11):1688-93.

95. Mengoli C, Cruciani M, Barnes RA, et al. Use of PCR for diagnosis of invasive aspergillosis: systematic review and meta-analysis. Lancet Infect Dis 2009; 9(2):89-96.

96. Herbrecht R, Denning DW, Patterson TF, et al. Voriconazole versus amphotericin B for primary therapy of invasive aspergillosis. N Engl J Med 2002;347(6): 408-15.

97. Pascual A, Calandra T, Bolay S, et al. Voriconazole therapeutic drug monitoring in patients with invasive mycoses improves efficacy and safety outcomes. Clin Infect Dis 2008;46(2):201-11.

98. Egli A, Fuller J, Humar A, et al. Emergence of Aspergillus calidoustus infection in the era of posttransplantation azole prophylaxis. Transplantation 2012;94(4): 403-10.

99. Imhof A, Balajee SA, Fredricks DN, et al. Breakthrough fungal infections in stem cell transplant recipients receiving voriconazole. Clin Infect Dis 2004;39(5): 743-6.

100. Lanternier F, Sun HY, Ribaud $P$, et al. Mucormycosis in organ and stem cell transplant recipients. Clin Infect Dis 2012;54(11):1629-36.

101. Kubak BM, Huprikar SS. Emerging \& rare fungal infections in solid organ transplant recipients. Am J Transplant 2009;9(Suppl 4):S208-26. 
102. Nucci M, Anaissie E. Fusarium infections in immunocompromised patients. Clinic 2007;20(4):695-704.

103. Husain S, Munoz P, Forrest G, et al. Infections due to Scedosporium apiospermum and Scedosporium prolificans in transplant recipients: clinical characteristics and impact of antifungal agent therapy on outcome. Clin Infect Dis 2005; 40(1):89-99.

104. Rodriguez M, Fishman JA. Prevention of infection due to Pneumocystis spp. in human immunodeficiency virus-negative immunocompromised patients. Clinic 2004;17(4):770-82 table of contents.

105. Martin SI, Fishman JA. Pneumocystis pneumonia in solid organ transplant recipients. Am J Transplant 2009;9(Suppl 4):S227-33.

106. Huang L, Morris A, Limper AH, et al. An Official ATS workshop summary: recent advances and future directions in pneumocystis pneumonia (PCP). Proc Am Thorac Soc 2006;3(8):655-64.

107. Briel M, Bucher HC, Boscacci R, et al. Adjunctive corticosteroids for Pneumocystis jiroveci pneumonia in patients with HIV-infection. Cochrane Database Syst Rev 2006;(3):CD006150.

108. Patel G, Arvelakis A, Sauter BV, et al. Strongyloides hyperinfection syndrome after intestinal transplantation. Transpl Infect Dis 2008;10(2):137-41.

109. Safdar A, Malathum K, Rodriguez SJ, et al. Strongyloidiasis in patients at a comprehensive cancer center in the United States. Cancer 2004;100(7):1531-6.

110. Marty FM. Strongyloides hyperinfection syndrome and transplantation: a preventable, frequently fatal infection. Transpl Infect Dis 2009;11(2):97-9. 